magnetic data. Instead, magnetization seems to have been acquired over a limited time span during the late Palaeozoic, from about 310 to 250 million years ago $^{2-4}$.

How can magnetite be responsible for this magnetic overprint? Two explanations have emerged. First, the magnetite may have formed chemically after deposition either by conversion from pyrite $\left(\mathrm{FeS}_{2}\right)$ or by new growth perhaps related to alteration of clay ${ }^{6}$ or to microbial degradation of hydrocarbons $\mathrm{s}^{2-7}$. Sparse magnetite concentrated from remagnetized carbonate rocks and examined under the scanning electron microscope has a grain shape and a surface texture that suggests a post-depositional, chemical origin ${ }^{5,8}$. Often, the magnetite particles are spherical (typically 3 to 40 micrometres in diameter), resembling framboidal pyrite (see figure). The second possibility is that remagnetization results from a reorientation of the magnetism in magnetite - regardless of its origin - following its exposure to moderately high temperatures".

The careful analytical work by Suk et al. ${ }^{\prime}$, using scanning transmission electron microscopy and electron diffraction, helps to resolve these uncertainties. They first identified magnetite in thin and polished slabs of the carbonates, and examined its spatial relationship to other minerals in the rock. In addition, polishing and milling enabled the authors to see inside individual crystals of magnetite (most of which are less than one micrometre across) and thus to discover that some crystals had centres of pyrite and margins of magnetite. This, and the observation that the aggregates of magnetite crystals have a shape identical to that of framboidal pyrite, indicates that magnetite has formed from pyrite and not the other way around.

The approach of cutting and polishing specimens for examination under reflectedlight and electron microscopes can have enormous advantages. Other palaeomagnetic studies would benefit from such an approach, because internal textures and compositional differences within magnetic grains can reveal their origins and alteration histories.

Suk et al. point out that the direction of remanent magnetization in remagnetized rock probably records the direction of the Earth's magnetic field while the magnetite formed from pyrite. How other factors, such as thermal effects ${ }^{4,10}$ and tectonic strain $^{11}$, may have influenced the remag. netization process requires further examination; but the chemical basis for these studies is now clear.

Alteration of pyrite to magnetite has occasionally been found in pyritic shales that have been heated locally by nearby igneous intrusions over a geologically short duration and at temperatures probably greater than $200{ }^{\circ} \mathrm{C}$; but it has not been reported previously for widespread alterations that occur over millions of years and at temperatures mainly less than $200^{\circ} \mathrm{C}$. In previous magnetic studies of sedimentary rocks, pyrite has been considered important only in respect of its tendency to replace depositional magnetite ${ }^{12.13}$, a process that can diminish the strength of magnetic properties but does not affect their orientation.

The observations of Suk et al. have implications for large-scale geological processes. The late Palaeozoic remagnetization event has been ascribed to chemical alteration caused by warm, saline fluids that were expelled from sedimentary rocks squeezed near zones of collision between crustal plates during building of the Appalachians ${ }^{2,14}$. Other manifestations of such an event in midcontinental North America include the distributions and patterns of hydrocarbon and metal deposits, as well as post-depositional growth of minerals other than magnetite, such as potassium feldspars. The new results add further support to the idea of a link between remagnetization of limestones and chemically active fluids, whatever their origin ${ }^{16}$. In these rocks at temperatures generally less than $200{ }^{\circ} \mathrm{C}$, heat alone could not have converted pyrite to magnetite: oxidizing agents in fluids must have also played a part. The extent of the alteration would have been controlled by the types and concentrations of these agents, by temperature ${ }^{\mathrm{II}}$, by the focusing of pathways of fluid flow $w^{2.6 .16}$, and by the presence and concentration of preexisting pyrite. All of which suggests that remagnetization of rocks will become viewed not as inconvenient but as serendipitous in providing a record of thermochemical alteration related to the fluidflow history of sedimentary basins.

Richard L. Reynolds is with the US Geological Survey, Box 25046, MS 964, Denver, Colorado 80225, USA.

1. Suk, D., Peacor, D.R. \& Van der Voo, R. Nature 345, 611 $613(1990)$.

2. McCabe, C., \& Elmore, D.R. Rev. Geophys. 27(4), 471494 (1989)

3. Van der Voo, R. Geol. Soc. Am. Mem. 172, 447-470 (1989).

4. Miller, J.D. \& Kent, D.V. Geology 16, 588-591 (1988).

5. McCabe, C., Van der Voo, R., Peacor, D.R., Scotese, C.R. \& Freeman, R. Geology 11, 221-223 (1983).

6. McCabe, C., Jackson, M. \& Saffer, B. J. geophys. Res. 94. 10429-10443(1989).

94, 10429-10443 (1989).

7. Elmore, R.D. et al. Nature 325, 428-430 (1987)

8. McCabe, C., Sassen, R. \& Saffer, B. Geology 15, 7-10 (1987)

9. Kent, D.V. Geophys. Res. Lett. 12, 805808 (1985)

10. Jackson, M., McCabe, C., Ballard, M.M. \&Van der Voo, R. Geology 16, 592-595 (1988)

11. Craddock, J.P. \& van der Pluijm, B.A. Geology 17, 416 419 (1989).

12. Karlin, R. \& Levi, S. J. geophys. Res. 90, 10373-10392 (1985)

13. Canfield, D.E. \& Berner, R.A. Geochim. cosmochim Acta 51, 645-660 (1987)

14. Oliver, J. Geology 14, 99-102 (1986)

15. Bethke, C.M., Harrison, W.J., Upson, C. \& Altaner, S.P. Science 239, 261-267 (1988)

16. Clendenin, C.W. \& Duane, M.J. Geology 18, 116-119 (1990).

17. Morse, J.W. \& Cornwell, J.C. Mar. Chem. 22, 55-69 (1987)

\section{The midnight Sun}

THE Earth's rotation provides us with light in intermittent doses. Daylight is amply bright, often inconveniently so; but at night even the best lighting provides only a feeble substitute. The obvious solution, says Daedalus, is to store samples of daylight for release at night.

A primitive form of this technology already exists. Luminous materials such as doped zinc sulphide can be 'charged' with light, which excites certain energy states in the crystal lattice: as these re-emit the stored energy, the material glows feebly in the dark for a few hours afterwards. Light recovery, however, is dismal: a mere few parts per million. Furthermore, the emitted light has only one colour, typically a depressing green.

But Daedalus is undaunted. He points out that photographic emulsions, thanks to close attention to crystal form, doping and the cunning use of sensitizing dyes, can attain wide-spectrum photon-capture efficiencies of several per cent, while luminous re-emission can be very efficient indeed (as in fluorescent lamps). So DREADCO's physicists are hard at work on the design of a truly advanced solid-state light-storage medium, or 'Lightstorm'.

For a balanced, white emission, Lightstorm will need three separate excited states of different energies, most easily obtained by mixing three different phosphors. To avoid wasteful internal scattering, they will be suspended in a medium of the same refractive index. A Lightstorm coating will appear clear but darkened by its light absorption, like transparent 'smoked plastic' resin. A storage capacity of around 50 joules per gram should enable a Lightstorm surface to charge up totally during the day and to glow cheerfully all night with a brightness of about one per cent of that of natural daylight. Existing artificial lighting does no better - our eyes adjust wonderfully to alterations of brightness. The even, non-dazzling glow of a Lightstorm ceiling should be very easy on the eyes. It would, of course, slowly fade as the night wore on, but then so does human activity.

Lightstorm will revolutionize the illumination industry. As wallpaper and ceiling paint it will light our houses at night; on the roads it will provide automatic free street lighting, road markings and illuminated signs. Nocturnal crime will plummet, while the poster and neon-sign industries will plumb new depths of garish vulgarity. All sorts of objects, from telephones and pens to socks and bicycles, will be made luminous for easy identification in the dark. The 24-hour Lightstorm greenhouse will boost horticultural productivity. And the saving of electricity will wonderfully curtail carbon dioxide production.

David Jones 